\title{
Fabrication of Functional High Density Cell Sheets for Tissue Engineering Using Spin-Coated Poly(N-isopropylacrylamide) Thin Films
}

\author{
Nina A Dzhoyashvilii,2*, Karl Joyce ${ }^{1}$, Kerry Thompson ${ }^{3}$ and Yury A Rochev ${ }^{1,4}$ \\ ${ }^{1}$ School of Chemistry, National University of Ireland Galway, Ireland \\ ${ }^{2}$ National Centre for Biomedical Engineering Sciences, National University of Ireland Galway, Ireland \\ ${ }^{3}$ Center for Microscopy and Imaging, Anatomy, School of Medicine, National University of Ireland Galway, \\ Ireland \\ ${ }^{4}$ Institute for Regenerative Medicine, Sechenov First Moscow State Medical University, Russia
}

\begin{abstract}
The current goal of cell sheet engineering technology is to provide an improved approach for more predictive and effective generation of viable tissue-like constructs. Success requires validation and characterization of cell sheet growth and detachment. In this study, we perform qualitative and quantitative assessments of cell sheets lifted from thin spin-coated poly(N-isopropylacrylamide) films.

Cell morphology, detachment time, metabolic activity and viability of mouse stromal and human corneal epithelial cell sheets were examined before and after lifting and after reattachment. The histological analysis of cell sheets and the immunofluorescence analysis of acting cytoskeleton, paxillin and cadherins were performed. The structure of extracellular matrix and the content of type I collagen in stromal and epithelial cell sheets were assessed by scanning electron microscopy and SDS-PAGE analysis, respectively.

Results demonstrate that lifted cell sheets remain viable and maintain tissue-like integrity that strongly depends on reinforcement of acting cytoskeleton and cadherins at cell-cell junctions. Strong cell-cell adhesions and a high density of confluent cell sheets promote collective cell sheet detachment. Preserved extracellular matrix and focal adhesion complexes support cell sheet reattachment.

This study demonstrates the potential of spin-coated poly(N-isopropylacrylamide) films in producing viable cell sheets that might be considered as a building block to create large biological tissues. Our results also describe the central cellular mechanisms involved in temperature-controlled collective cell migration. This study should promote further research in engineering three-dimensional tissues with complex organizational architecture.
\end{abstract}

\section{Keywords}

Spin-coating, Poly(N-isopropylacrylamide), Cell sheets, Cytoskeletal reorganization, Collective cell migration, Tissue engineering

\section{Abbreviations}

3D: Three-Dimensional; DAPI: 4',6-Diamidino-2-Phenylindole; DMEM: Dulbecco's Modified Eagle Medium; DMSO: Dimethyl Sulfoxide; ECM: Extracellular Matrix; FAs: Focal Adhesions; FBS: Fetal Bovine Serum; HBSS: Hank's Balanced Salts Solution; HCEC: Human Corneal Epithelial Cells; H\&E: Hematoxylin and Eosin; LCST: Low Critical Solution Temperature; MS-5: Mouse Bone Marrow-derived Stromal Cell Line; pNIPAm: Poly(N-isopropylacrylamide); SD: Standard Deviations; SDS: Sodium Dodecyl Sulfate; SDS-PAGE: Sodium Dodecyl Sulfate Polyacrylamide Gel Electrophoresis; SEM: Scanning Electron Microscopy; TCPS: Tissue Culture Polystyrene

\section{Introduction}

Cell sheet tissue engineering technologies have been rapidly developed and applied in different areas of bio- medical research, including regenerative medicine [13], cell-based drug screening assays [4,5], and tissue and disease modelling [6-9]. Most experimental studies have used cell sheets for scaffold-free tissue engineering

Copyright: @ 2017 Dzhoyashvili NA, et al. This is an open-access article distributed under the terms of the Creative Commons Attribution License, which permits unrestricted use, distribution, and reproduction in any medium, provided the original author and source are credited. 
[10-12]. Several studies have shown that cell sheet transplantation has been effective in the treatment of severe diseases such as cardiomyopathy and congestive heart failure [13], neovascular age-related macular degeneration [14], many forms of liver disease [15], diabetes mellitus [16], massive burns [17] and cartilage degeneration and defects [18]. Because cell sheets can be transplanted without sutures, this procedure saves time, reduces risk from biological materials and can avoid suture-related problems, such as inflammation and scars. This approach offers several distinctive therapeutic advantages, especially for cornea, esophageal epithelium or oral mucosa regeneration [19-21].

Currently, the most effective way of cell sheet generation involves the use of pNIPAm-based thermoresponsive substrates [22-25]. pNIPAm dissolves in cell culture media when the temperature drops below its Low Critical Solution Temperature (LCST) of about $32^{\circ} \mathrm{C}$ and ultimately results in cell detachment. However, the exact mechanism of cell sheet detachment from thermoresponsive surfaces is still under investigation. Among many methods, spin-coating technique has been shown to provide an inexpensive and convenient way to prepare thermoresponsive polymer films which thickness and surface characteristics can be carefully controlled [26,27]. Proteolytic enzymes generally used to detach adherent cells can potentially damage cell surface proteins, including ion channels and growth factor receptors, destroy ECM and affect cellular signal transduction pathways [28]. In contrast, thermoresponsive polymer-based technology enables fabrication of contiguous and viable cell sheets composed of cells and functional Extracellular Matrix (ECM) avoiding the use of proteolytic reagents. In cell sheets, the cells are embedded in ECM and delivered together with secreted growth factors that might increase survival rate and the ability of cells to engraft into damaged tissue after transplantation [29,30]. Mechanosensitive properties of cell sheets, undergoing force-dependent remodeling after detachment, play an essential role in cell sheet integrity. Different components of the cytoskeleton network are important in regulation of cell sheet integrity that influences the cell sheet strength in the absence of a substrate $[31,32]$. In recent years, an increasing number of studies have investigated the relationship between cytoskeleton reorganization and collective cell motion in both embryonic development and normal growth of adult tissue, wound healing and metastatic invasion [33-37]. It has been suggested that cellular density may play a crucial role in these processes. As a cell sheet density increases as a result of proliferation, cells become crowded and exert a pressure on their neighbors. As the effect of pressure progressively increases, independent cellular motions become frozen, and the cells become increasingly cooperative and have to move in a collective manner [38,39]. In our previous study, it was found that $50 \mathrm{~nm}$ thick spin-coated poly(N-isopropylacryl- amide) (pNIPAm) films enables harvesting of contiguous cell sheets [26]. In this study, we carried out the qualitative and quantitative assessments of two types of cell sheets harvested from thin pNIPAm films. The comparison of cells with different proliferation rate, ECM synthesis and cytoskeleton organization might unveil key factors underlying cell sheet integrity and homeostasis. Considering this view, mouse bone marrow-derived stromal cell line (MS-5) and Human Corneal Epithelial Cells (HCEC) were examined for their biological properties and potentials for cell sheet harvest. In particular, cell morphology, total cell number in cell sheets, the pattern and speed of cell sheet recovery were analyzed. The metabolic activity and cell viability of attached and lifted cell sheets were also examined. To investigate cell sheet remodeling during and immediately after detachment, we performed the histological analysis of cell sheets and the immunofluorescence analysis of paxillin, cadherins and actin fibers. Paxillin was examined because it is an important structural focal adhesion component which plays a central role in the coordination of numerous regulatory proteins involved in cytoskeletal reorganization during cell adhesion as well as cell movements [40-42]. Cadherins were chosen because they are critical to maintaining tissue integrity and play an essential role during collective cell motion [43-45]. The knowledge obtained from this systematic characterization of cytoskeleton components may be important for further improvement of cell sheet mechanical and structural properties. To assess the role of ECM in cell sheet detachment and reattachment, the lifted MS-5 and HCEC cell sheets were compared in terms of ECM structure and deposition of type 1 collagen. The present study provides a validation system for cell sheet systematic assessment. Importantly, these findings can also contribute to better understanding the role of ECM and cytoskeleton remodeling in mechanisms of collective cell movements in normal and pathological conditions.

\section{Materials and Methods}

\section{Materials}

The polymer poly( $\mathrm{N}$-isopropylacrylamide) with $\mathrm{Mn}$ $=20000-40000$, anhydrous ethanol (200 proof, $>99.5 \%$ assay), Triton-X-100, paraformaldehyde, Harris modified hematoxylin and Eosin Y, Sodium Dodecyl Sul-

*Corresponding author: Nina A Dzhoyashvili, School of Chemistry, National Centre for Biomedical Engineering Sciences, National University of Ireland, Galway, H91 CF50, Galway, Ireland, E-mail: n.dzhoyashvili@gmail.com

Received: September 21, 2017; Accepted: November 21, 2017; Published online: November 23, 2017

Citation: Dzhoyashvili NA, Joyce K, Thompson K, et al. (2017) Fabrication of Functional High Density Cell Sheets for Tissue Engineering Using Spin-Coated Poly(N-isopropylacrylamide) Thin Films. Insights Stem Cell Res Ther 1(1):1-14 
fate (SDS), glutaraldehyde solution (25 wt. \%), acetic acid glacial $(\geq 99.85 \%)$, porcine gastric mucosa pepsin $(\geq 2,500 \mathrm{U} / \mathrm{mg}), 0.5 \mathrm{M}$ EDTA, $10 \mathrm{mM}$ Tris- $\mathrm{HCl}$, sodium cacodylate tri hydrate $(\geq 98.0 \%)$ and DMSO (anhydrous, $\geq 99.9 \%$ ) were purchased from Sigma-Aldrich (St. Louis, USA). Plastic consumables were purchased from Sarstedt (Nümbrecht, Germany). Borosilicate cover glass slides (25 mm in diameter) were purchased from VWR (Radnor, USA). Hanks Balanced Salt Solution (HBSS) and Dulbecco's Modified Eagles Medium (DMEM) were purchased from Lonza (Basel, Switzerland). Antibiotics (penicillin-streptomycin) and Fetal Bovine Serum (FBS) were purchased from HyClone (Logan, USA). Alamar Blue ${ }^{\circledast}$ reagent, Live/Dead ${ }^{\circledast}$ viability/cytotoxicity kit, Quant-iT ${ }^{\mathrm{TM}}$ Pico Green ${ }^{\circledast}$ dsDNA assay kit and Silver Quest silver staining kit were purchased from Invitrogen-Thermo Fisher Scientific (Waltham, USA). Rabbit monoclonal anti-paxillin antibody (ab32084), rabbit polyclonal anti-pan cadherin antibody (ab6529) and goat anti-rabbit secondary antibody (ab150077) were purchased from Abcam (Cambridge, UK). Phalloidin eFluor 660 (50-6559-05) was purchased from Affymetrix (Santa Clara, USA). UltraCruz ${ }^{\mathrm{TM}}$ mounting medium was purchased from Santa Cruz Biotechnology (Santa Cruz, USA). Heating dry bath from Torrey Pines Scientific (Carlsbad, USA) was used for careful temperature control.

\section{Thermoresponsive pNIPAm film fabrication}

Spin-coated poly(N-isopropylacrylamide) films were fabricated as described previously [26]. Briefly, a $150 \mu \mathrm{l}$ aliquot of a $5 \mathrm{mg} / \mathrm{ml}$ ethanol polymer solution was deposited onto a slowly spinning, (150 RPM), substrate (Tissue Culture Polystyrene (TCPS) dishes $(35 \mathrm{~mm})$ or glass slides) for $9 \mathrm{~s}$ followed by rapid acceleration to 4000 RPM for $30 \mathrm{~s}$, on a Laurell Technologies WS-400B-256. The spin-coated samples were slowly dried overnight in an ethanol saturated atmosphere and then left in a vacuum oven at $40{ }^{\circ} \mathrm{C}$ and $600 \mathrm{~m}$ Bar for a minimum of $4 \mathrm{~h}$ to eliminate any residual solvent. TCPS dishes were used as an under layer substrate for cell morphology analysis, qualitative cell assays (alamarBlue and PicoGreen) and cell detachment analysis. Clean and optically flat borosilicate cover glass slides were used as an under layer substrate for fluorescence microscopy analysis.

Optical profilometry analysis was used to confirm the thickness of $50 \mathrm{~nm}$ thick pNIPAm films as described previously [26]. Briefly, an ArF excimer laser (ATL Atlex ${ }^{\oplus}$, Wermelskirchen, Germany) was used to ablate the selected areas on thin pNIPAm films deposited on fused silica glass discs. The thickness of pNIPAm films was measured using white light interferometry (Zygo New View 100) with an accuracy of $0.1 \mathrm{~nm}$. The $\mathrm{z}$-height distance between the remaining polymer and the underly- ing substrate was measured to accurate assess the thickness. Statistically relevant data was obtained by repeating all measurements three times, and scans of 5 randomly selected ablated windows were recorded on 3 different samples.

\section{Cell sheet generation and morphology observation}

For cell culture experiments, $50 \mathrm{~nm}$ thick pNIPAm films were sterilized under mild UV light for 2 hrs. For experimentation, MS-5 or HCEC cells were seeded on pNIPAm-coated or control uncoated TCPS dishes in triplicate at a density of 40000 cells $/ \mathrm{cm}^{2}$. The cells were cultivated in DMEM, supplemented with 10\% FBS, $1 \%$ penicillin-streptomycin antibiotics and maintained in a humidified incubator at $37^{\circ} \mathrm{C}$ and $5 \% \mathrm{CO}_{2}$. The DMEM was changed at two-day intervals. When the cells were confluent, the medium was changed daily.

The detachment of cells grown on pNIPAm films was mediated by reducing temperature. The cells were rinsed with pre-warmed HBSS to remove any traces of serum. Cold serum-free DMEM was added to cells and the samples were left on a digitally controlled thermal/cooling plate set to $4{ }^{\circ} \mathrm{C}$ until detachment.

Then the lifted cell sheets were transferred onto other control TCPS dish and incubated in a growth medium volume of $200 \mu \mathrm{L}$ at $37^{\circ} \mathrm{C}$ in a humidified incubator for $1 \mathrm{hr}$. After attachment, a final culture medium volume of $1.5 \mathrm{ml}$ was added to each dish.

MS-5 and HCEC cell sheet growth and detachment were microscopically monitored, and micrographs of cells were taken using Leica inverted microscope (Leica, Solms, Germany). The experiments were repeated three times on independent days.

\section{Cell sheet proliferation, viability and metabolic activity analysis}

Quant-I T ${ }^{\mathrm{TM}}$ PicoGreen ${ }^{\circledR}$ dsDNA assay kit was used to assess the DNA content in lifted cells. Cell numbers in cell sheets were calculated when the cell sheets were gently lifted from pNIPAm-coated dishes, as described above. Cell numbers were obtained by calculation based on the cell DNA, using a calibration curve of total cell DNA versus known numbers of cells.

A Live/Dead cell viability assay was performed to test cell sheet viability. Titration was performed for both calcein AM and ethidium homodimer-1 to define optimal dye concentration according to the manufacture protocol. A solution of $1 \mu \mathrm{M}$ Calcein AM and $2 \mu \mathrm{M}$ ethidium homodimer-1 in HBSS were mixed thoroughly, and then added to the cells for $20 \mathrm{~min}$ at $37^{\circ} \mathrm{C}$. The staining with calcein AM resulted in bright green fluorescence in the cytoplasm of viable cells with intact cell membranes. 
Ethidium homodimer stained dead cells red. The control dead cells were prepared by the treatment of cultured cells with cell death inducing agent, Dimethyl Sulfoxide (DMSO), for $20 \mathrm{~min}$.

AlamarBlue ${ }^{\circledast}$ assay was used to examine metabolic activity. Cell metabolism was expressed as the fluorescence per cell after the fluorescence was divided by the number of vital cells in a sample.

All assays were performed following the manufacturer's instructions before and after cell sheet detachment and after reattachment. AlamarBlue and PicoGreen fluorescence was measured using a Thermo Scientific Varioskan Flash Multimode plate reader. The fluorescent staining of live and dead cells was observed using an Olympus IX81 fluorescence microscope (Olympus) and images were captured using a DP72 CCD camera (Olympus) linked to cellSens Dimension software (Olympus). Each assay was repeated three times on independent days.

\section{Immunofluorescent staining and image analysis}

The MS-5 and HCEC cell sheets were fixed with $4 \%$ paraformaldehyde and then permeabilized with Triton X-100 (0.1\%). Afterwards, the cell sheets were incubated with $3 \%$ goat normal serum for $1 \mathrm{~h}$ at $37^{\circ} \mathrm{C}$ to block non-specific binding. Cell sheets were then incubated with rabbit monoclonal anti-paxillin antibody at 1: 250 dilution or rabbit polyclonal anti-pan cadherin antibody at $1: 100$ dilution at $37^{\circ} \mathrm{C}$ for $1 \mathrm{hr}$. The slides were washed with HBSS followed by incubation for $1 \mathrm{~h}$ with a 1: 1000 dilution of Alexa Fluor ${ }^{\circledast} 488 \mathrm{~nm}$ goat anti-rabbit secondary antibody at $37^{\circ} \mathrm{C}$. Actin stress fibers were detected using Phalloidin eFluor 660 at 1: 500 dilutions. After rinsing with HBSS, the samples were mounted with Ultra Cruz TM mounting medium containing $1.5 \mu \mathrm{g} / \mathrm{ml}$ DAPI for nuclear counter staining. All stained slides were observed using Andor spinning disc confocal microscope.

To quantify actin or cadherin levels in cells, an outline of $30 \times 30$ pixels was drawn around each cell junction region $(n>10)$, and the area, integrated density along with mean fluorescence of background readings were measured using Image J software (NIH, Bethesda, USA). The calculation of Total Corrected Cellular Fluorescence (TCCF) was performed according to formula, TCCF $=$ integrated density - (area of selected cell $\mathrm{x}$ mean fluorescence of background readings) [46]. Relative actin or cadherin intensity levels at cell junctions in lifted cell sheets were normalized to unlifted cell sheet controls. For nuclear quantification, images from 10 independent fields per slide and 50-200 cells per image excluding those crossing the right and the bottom boundary were counted. All images were analyzed as Tiff files. The absence of nonspecific binding was confirmed by the use of appropriate primary and secondary antibody controls.

\section{Histological examination}

After being incubated for 2 weeks, the MS-5 and HCEC sheets were detached from dishes and fixed with $4 \%$ paraformaldehyde solution for $24 \mathrm{hrs}$. Specimens were then embedded in paraffin using an automated tissue processing machine (Leica ASP300), sectioned using a microtome (Leica RM2235) and stained with Hematoxylin and Eosin (H\&E) according to manufacturer's instruction. Images were captured with Olympus IX-81 inverted microscope. Thicknesses of cross-sectioned cell sheets were measured using Image J software.

\section{Extraction of ECM from cell sheets}

To prepare and analyze ECM, lifted MS-5 or HCEC cell sheets cultured for 2 weeks were decellularized using low concentration of SDS as previously described [47]. Briefly, the cell sheets were shaken for $30 \mathrm{~min}$ in decellularization solution containing $0.05 \mathrm{wt} \%$ SDS, $10 \mathrm{mM}$ Tris, and $25 \mathrm{mM}$ EDTA and then thoroughly washed with HBSS.

\section{Scanning electron microscopy}

The decellularized cell sheets were analyzed using SEM. For SEM imaging, the ECM specimens were first fixed in a $0.2 \mathrm{M}$ sodium cacodylate buffer $(\mathrm{pH} 7.2$ ) containing $2 \%$ paraformaldehyde and $2.5 \%$ glutaraldehyde for $10 \mathrm{~min}$ at room temperature, dehydrated in a graded ethanol series, air-dried and finally sputter-coated with gold and examined using a Hitachi S-4700 SEM. The specimens were examined at $15 \mathrm{kV}$ in high vacuum mode.

\section{SDS-PAGE analysis of type I collagen}

The MS-5 and HCEC cell sheets were washed twice with HBSS and digested with porcine gastric mucosa pepsin in a final concentration of $0.1 \mathrm{mg} / \mathrm{ml}$ in $0.05 \mathrm{M}$ acetic acid. Samples were incubated at $37^{\circ} \mathrm{C}$ for $2 \mathrm{~h}$ with gentle shaking. After incubation, the samples were neutralized with $0.1 \mathrm{~N} \mathrm{NaOH}$. The samples were then analyzed by SDS-PAGE under non-reducing conditions [48]. Briefly, $0.1 \mathrm{mg} / \mathrm{ml}$ of bovine type I collagen was used as standards with every gel. The $10 \%$ SDS gel made up of 3\% stacking and 5\% resolving components were used. Collagen bands were stained using Silver Quest kit (Invitrogen) according to manufacturer's protocol. For this experiment, type I collagen $\alpha 1$ and $\alpha 2$ chains were quantified. Densitometric analysis was performed to quantify collagen bands in wet gels. The amount of each collagen band was calculated using a rectangular tool with background subtraction provided by Image $J$ software (NIH, Bethesda, MD, USA).

\section{Statistical analysis}

Statistical analysis was performed using Statistica 8.0 software. Values are expressed as mean \pm Standard Devi- 
Citation: Dzhoyashvili NA, Joyce K, Thompson K, et al. (2017) Fabrication of Functional High Density Cell Sheets for Tissue Engineering Using Spin-Coated Poly(N-isopropylacrylamide) Thin Films. Insights Stem Cell Res Ther 1(1):1-14

Table 1: Summary of characteristics of lifted stromal MS-5 and epithelial HCEC sheets.

\begin{tabular}{|c|c|c|c|c|c|c|c|c|c|}
\hline Cell type & $\begin{array}{l}\text { Detachment } \\
\text { time (min) }\end{array}$ & $\begin{array}{l}\text { Cell } \\
\text { number } \\
\left(\times 10^{6}\right)\end{array}$ & $\begin{array}{l}\text { Cell sheet } \\
\text { thickness } \\
(\mu \mathrm{m})\end{array}$ & $\begin{array}{l}\text { Cell sheet } \\
\text { diameter } \\
(\mathrm{mm})\end{array}$ & $\begin{array}{l}\text { Cell sheet } \\
\text { area } \\
\left(\mathrm{cm}^{2}\right)\end{array}$ & $\begin{array}{l}\text { Cell sheet } \\
\text { metabolic } \\
\text { activity }\end{array}$ & Stratification & Paxillin & Cadherin \\
\hline $\begin{array}{l}\text { MS-5 } \\
1 \text { week }\end{array}$ & $10 \pm 3$ & $0.8 \pm 0.1$ & $17 \pm 3$ & $12 \pm 3$ & $1.1 \pm 0.6$ & $88 \%$ & Thin, 2-3 layers & + & + \\
\hline $\begin{array}{l}\text { MS-5 } \\
2 \text { weeks }\end{array}$ & $10 \pm 3$ & $4.1 \pm 0.4$ & $45 \pm 5$ & $22 \pm 3$ & $3.8 \pm 1.1$ & $84 \%$ & $\begin{array}{l}\text { Normal, } \\
\text { 4-5 layers }\end{array}$ & + & + \\
\hline $\begin{array}{l}\text { HCEC } \\
1 \text { week }\end{array}$ & Impossible & - & - & - & - & - & - & - & - \\
\hline $\begin{array}{l}\text { HCEC } \\
2 \text { weeks }\end{array}$ & $35 \pm 5$ & $2.2 \pm 0.3$ & $15 \pm 2$ & $23 \pm 2$ & $4.2 \pm 0.8$ & $94 \%$ & $\begin{array}{l}\text { Thin, } \\
\text { 2-3 layers }\end{array}$ & + & + \\
\hline
\end{tabular}

+: Presence -: Absence.

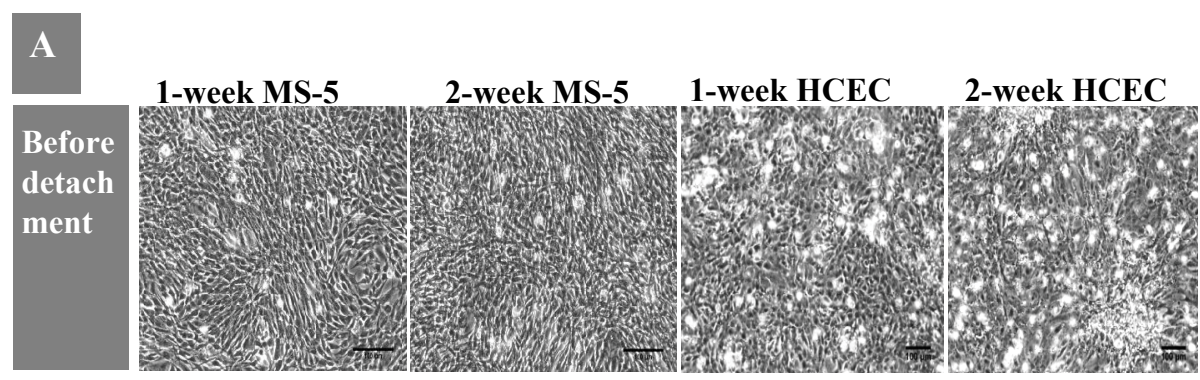

\section{B}
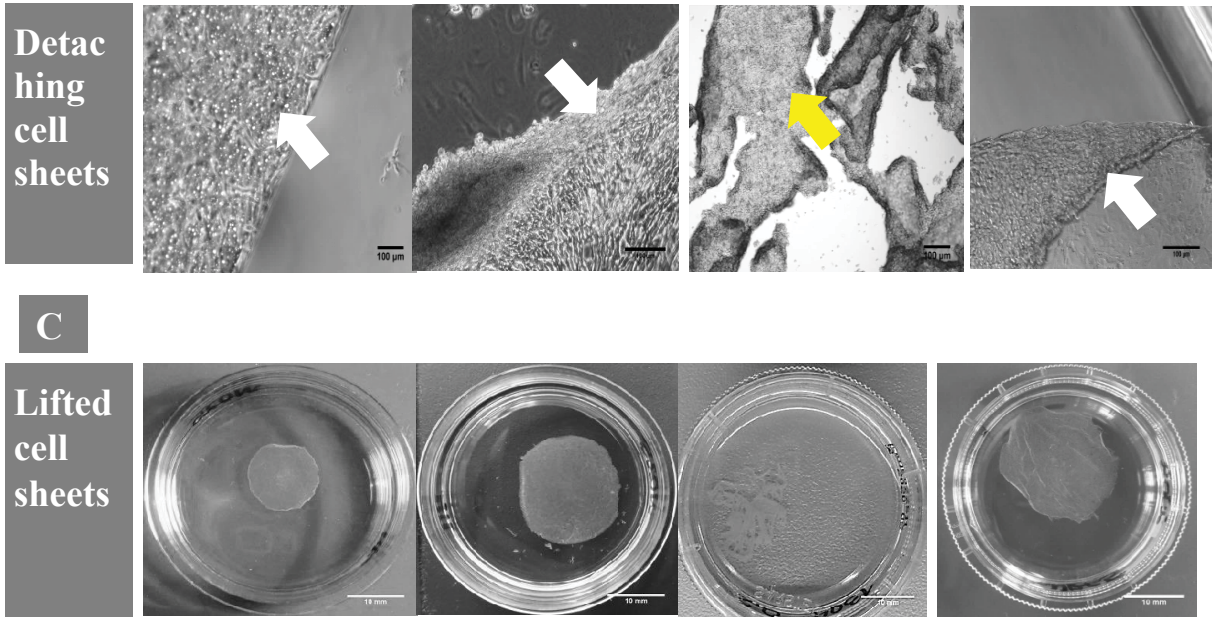

Figure 1: Morphological characteristics of MS-5 and HCEC cell sheets engineered by culturing harvested cells for one or two weeks A) Phase contrast images of MS-5 and HCEC growing on pNIPAm-coated surface prior to cell detachment. Scale bar: $100 \mu \mathrm{m}$; B) The cell sheets detaching from pNIPAm-coated culture dishes after reducing the temperature to $4{ }^{\circ} \mathrm{C}$. Scale bar: $100 \mu \mathrm{m}$; C) MS-5 and HCEC cell sheets contracted while lifting. One-week HCEC sheets did not detach intact. Initial cell-seeding density 40000 cells $/ \mathrm{cm}^{2}$. Scale bar: $10 \mathrm{~mm}$. The white arrow indicates a detaching cell sheet. The yellow arrow indicates a ruptured cell sheet.

ation (SD). If normal distribution was confirmed using Kolmogorov-Smirnov test and Shapiro-Wilk's W test, student $\mathrm{t}$-test were conducted to compare independent groups and multiple comparisons were made using one-way ANOVA test. Otherwise, non-parametric Kruskal-Wallis test for multiple comparisons and Mann-Whitney test for two independent groups were carried out. Statistical significance was defined as $\mathrm{p}$-value $<0.05$.

\section{Results}

\section{Generation and morphology of MS-5 and HCEC sheets}

The morphology and size of cell sheets, cell numbers and time required for detachment of intact MS-5 and HCECs sheets were compared (Table 1). Microscopy analysis showed that the cells, when initially seeded 
on pNIPAm-coated surface, attached, expanded and reached confluence after 24 hrs. MS- 5 cells were fully spread and had spindle-shaped morphology and HCEC displayed normal cobblestone-like cell morphology (Figure $1 \mathrm{~A}$ ). During and immediately after low temperature treatment, the cells became less spread and flattened and started to detach (Figure 1B). The visual tracking revealed that one-week and two-week MS-5 started to detach as a contiguous cell sheet first from the dish edges only, followed by the complete detachment from the substrate within around $10 \mathrm{~min}$. In contrast, one-week HCEC did not detach as an intact cell sheet, and only those HCEC cultured on pNIPAm surface for 2 weeks were able to detach as an intact sheet within around 40 min. Moreover, in order to facilitate cell sheet recovery, the partly lifted premature one-week HCEC sheets had to be gently rinsed with culture medium against the detached part of the cell sheets (Figure 1C).
There was no significant difference in a cell sheet area or in shrinkage rate between two-week MS-5 and twoweek HCEC lifted cell sheets. One-week MS- 5 sheets had a smaller area and a higher shrinkage rate than two-week MS-5 sheets (Figure 2).

\section{Viability and metabolic activity of MS-5 and HCEC sheets}

To ensure that long-term culture, cell sheet detachment and manipulation do not affect cell behavior, viability and metabolic activity assays were applied to cell sheets after 2 weeks in culture under several conditions: prior to cell sheet detachment, immediately after cell sheet lifting and $48 \mathrm{~h}$ after reattachment of lifted cell sheets. Importantly, the lifted cell sheets reattached faster, within around $20 \mathrm{~min}$, than a single cell suspension that attached within 3-4 h. The viability test was done on detached and reattached MS-5 and HCEC sheets with

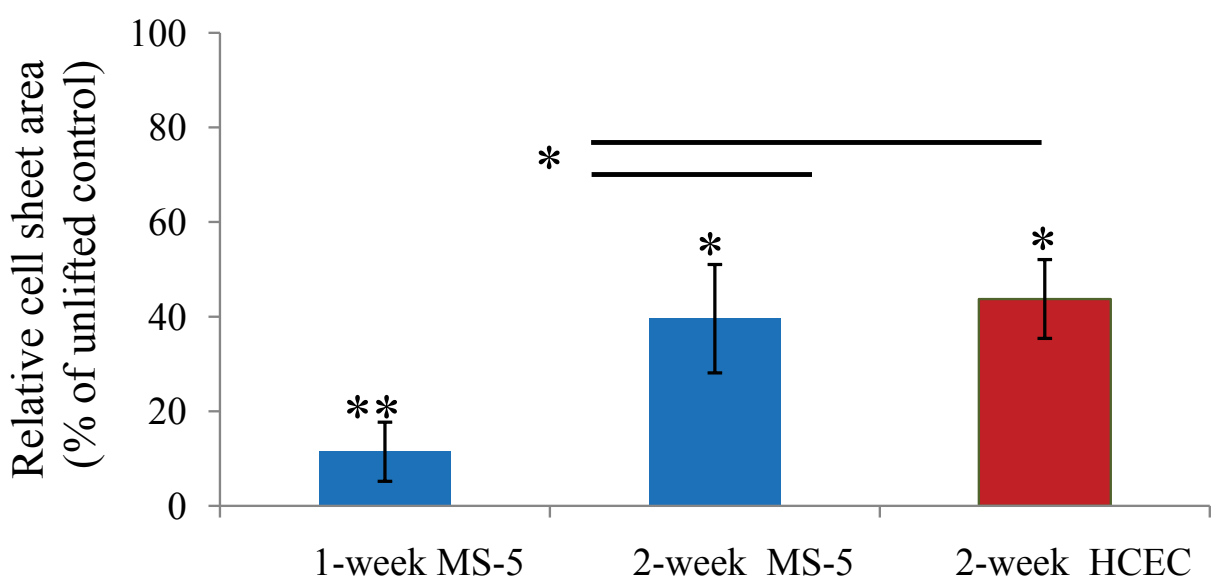

Figure 2: Intact MS-5 and HCEC sheets contracted after detachment from pNIPAm films. During and immediately after lifting, one-week MS-5, two-week MS-5 and two-week HCEC sheets shrunk to $11 \%, 40 \%$ and $44 \%$ of their original area, respectively. ${ }^{*} p<0.05,{ }^{* *} p<0.01$. Data are expressed as the mean \pm Standard Deviation (SD).

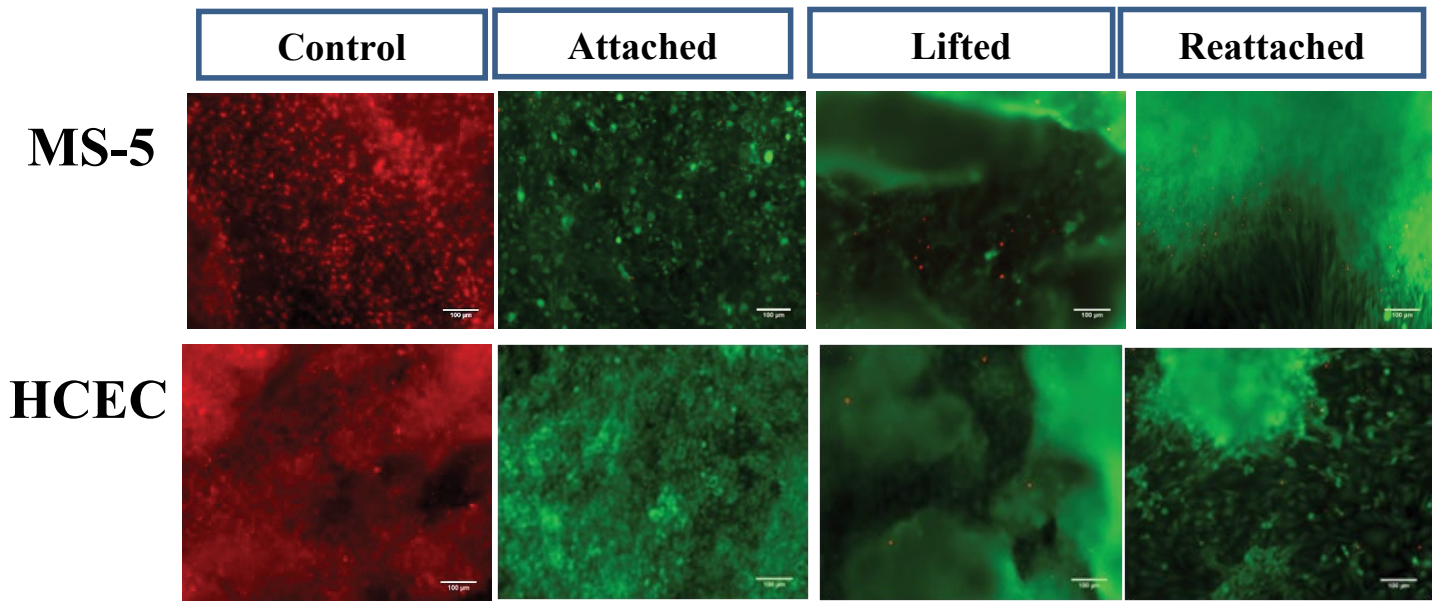

Figure 3: Live/Dead fluorescent staining of two-week MS-5 and two-week HCEC sheets before detachment, immediately after detachment and $48 \mathrm{~h}$ after reattachment to TCPS. Red fluorescence indicates the dead cells. Alive cells with intact cell membranes fluoresce green. The control for each cell type was treated with cell death-inducing agent DMSO. Scale bar $100 \mu \mathrm{m}$. 


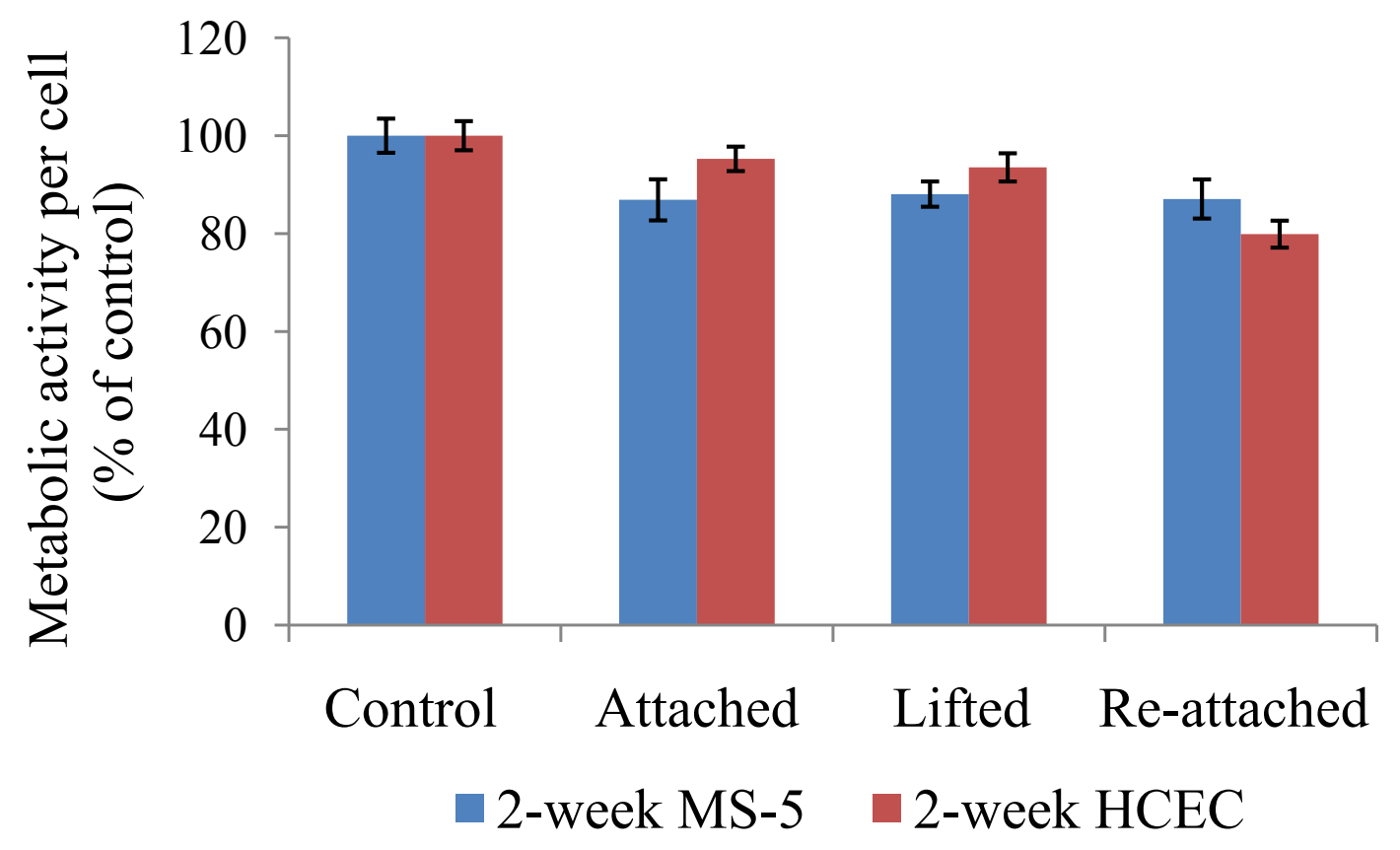

Figure 4: Results of alamarBlue assay for two-week MS-5 and two-week HCEC sheet before and after detachment and 48 $\mathrm{h}$ after reattachment to TCPS. Data is mean \pm Standard Deviation (SD), no significant difference compared to control cells grown on TCPS.

similar results. The percentage of viable cells stained with calcein AM reached almost $100 \%$ on all tested samples, indicating that the manipulation with cell sheets such as harvesting from pNIPAm-coated substrate, cell sheet transfer and further reattachment did not significantly damage the cells (Figure 3).

To examine the quality of fabricated cell sheets, the metabolic activity was assessed after cell sheet detachment and reattachment (Figure 4). The results showed that MS-5 and HCEC sheets have lower metabolic activity than control cells, but the difference was not statistically significant. Therefore, the results indicate that both MS- 5 and HCEC sheets remained viable and metabolically active at all processing steps, with no significant differences among tested groups and controls.

\section{Act in distribution and intercellular junction anal- ysis}

The cell-cell adhesion and act in distribution in cell sheets were next examined for analysis of cell sheet integrity. The lifted MS-5 and HCEC cell sheets shrunk significantly and changed in shape and size (Table 1 ). The comparison of distribution of act in filaments and cadherins indicated a structural difference between attached and lifted cell sheets. In particular, the attached MS-5 span abundant thin and parallel filamentous act in bundles extended through the cell cytoplasm. After detachment, the lifted MS-5 cell sheet shrunk, lost cytoplasm act in and formed cortical act in fibers along the cell membrane. The detached HCEC sheets also displayed stronger cortical fluorescent ring of filamentous act in (Figure 5A). DAPI nuclear staining showed that lifted MS-5 and HCEC cell sheets exhibited significant increase in nuclear density (Figure 5B). The cell sheet detachment resulted in cell sheet contraction and significant increase of cell-cell contact area. The quantitative analysis of fluorescence signal at cell-cell junctions confirmed that the level of cortical actin was significantly increased in around 2.8 times and 1.5 times for MS-5 and HCEC sheets, respectively (Figure 5C). The analysis of cell-cell adhesion protein cadherins revealed the preservation of adherence junctions after cell sheet detachment. Moreover, the lifted MS-5 and HCEC cells showed enhanced junctional localization of cadherins. The level of cadherins at cell-cell junctions was increased in 2.5 and 1.6 times for lifted MS-5 and HCEC sheets, respectively (Figure 5D). Results demonstrated that both actin filaments and cell adhesion proteins cadherins were reinforced at cell-cell junctions in lifted cell sheets indicating their cooperative roles during and immediately after cell sheet detachment.

\section{ECM deposition and focal adhesion analysis in MS-5 and HCEC cell sheets}

ECM deposition and focal adhesion analysis was performed to assess their contribution to cell sheet remodeling during cell sheet detachment and reattachment. Paxillin is a key component of focal adhesion network, found in regions closely adherent to the substratum and 
Citation: Dzhoyashvili NA, Joyce K, Thompson K, et al. (2017) Fabrication of Functional High Density Cell Sheets for Tissue Engineering Using Spin-Coated Poly(N-isopropylacrylamide) Thin Films. Insights Stem Cell Res Ther 1(1):1-14
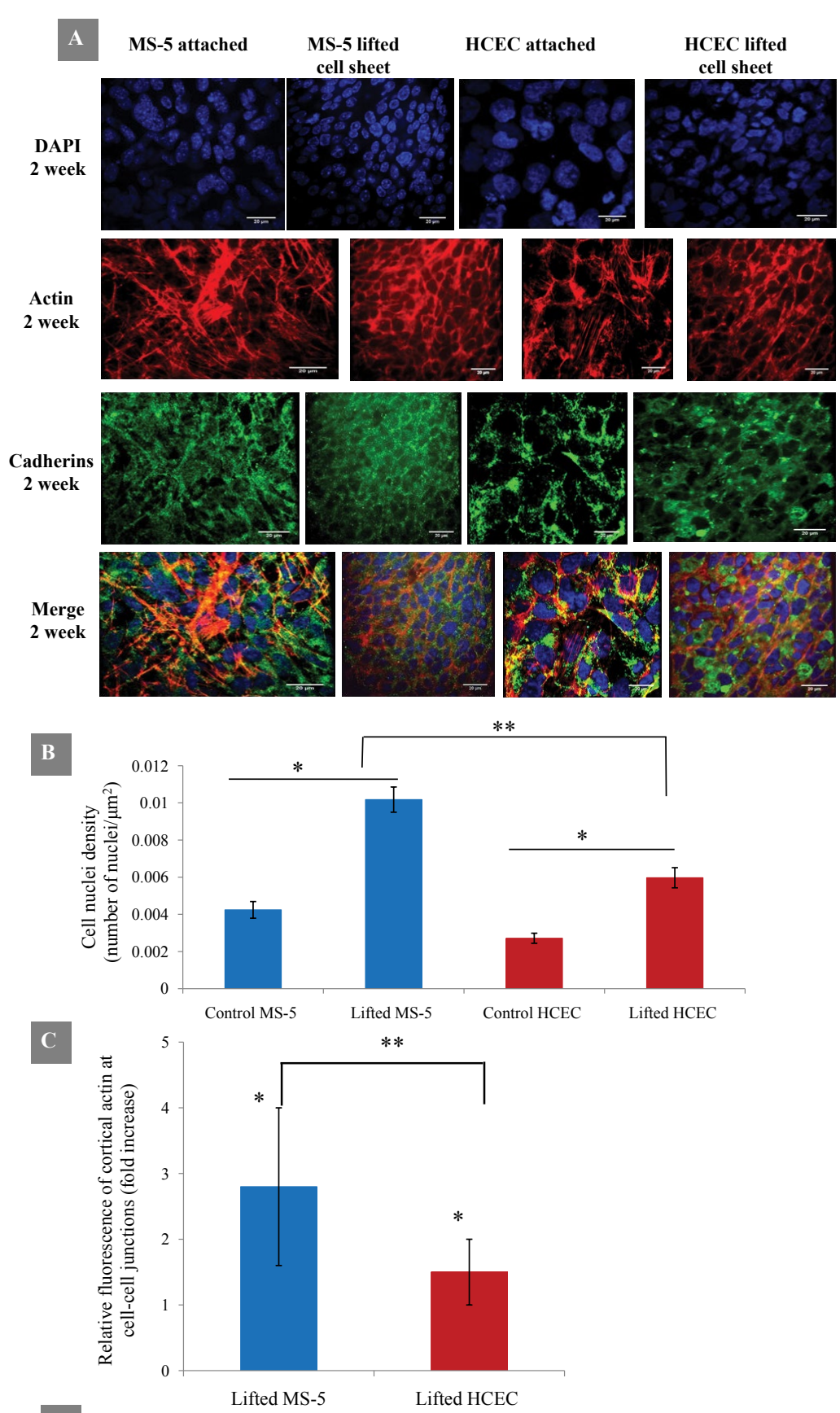

D

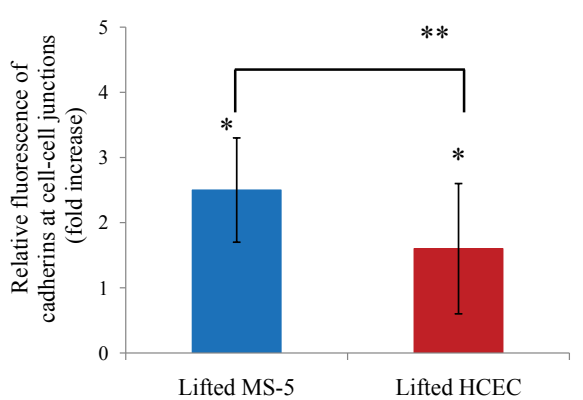

Figure 5: Cell sheet contraction induces the coordinated reorganization of the cytoskeleton of two-week MS-5 and two-week HCEC lifted cell sheets A) Fluorescence images of F-actin (red), cadherins (green), DAPI nuclear staining (blue) in control and lifted cell sheets show the spatial rearrangement of actin filaments and cadherins. Scale bar: $20 \mu \mathrm{m} ; \mathrm{B}$ ) Both MS-5 and HCEC lifted cell sheets showed significant increase in nuclei density indicating cell sheet contraction. " $p<0.05$ compared with unlifted control. " $p<0.05$ for lifted MS-5 versus lifted HCEC; C,D) Quantitative analysis of actin and cadherins at cell-cell junctions showed the increase of both cortical actin and cadherins in lifted MS- 5 and HCEC sheets. " $p<0.05$ compared with unlifted control. " $p<0.05$ for lifted MS-5 versus lifted HCEC. Data are expressed as the mean \pm Standard Deviation (SD). 

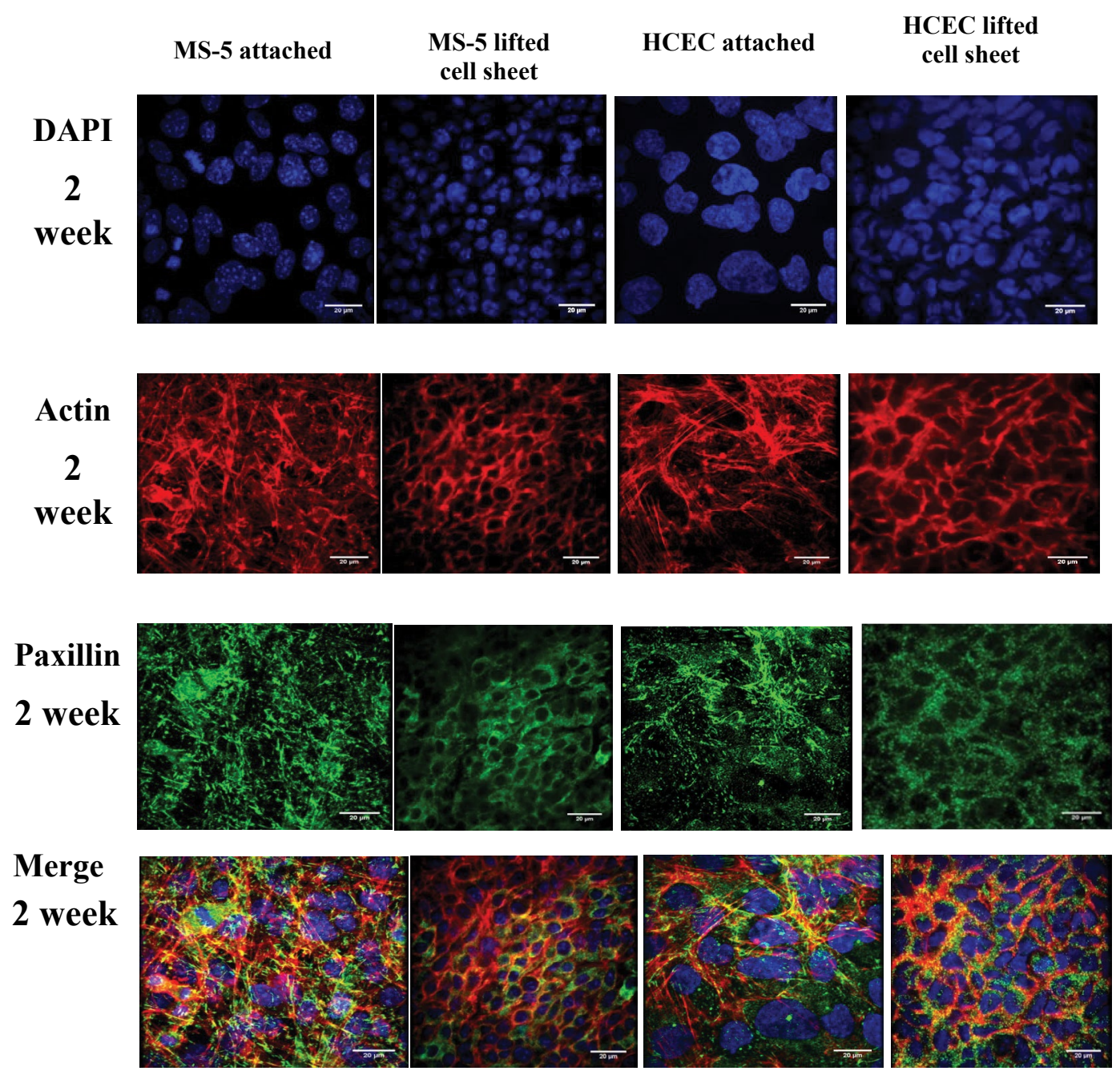

Figure 6: Reorganization of the cytoskeleton of two-week MS-5 and two-week HCEC before and after detachment. Phalloidin staining for F-actin (red), paxillin (green), DAPI nuclear staining (blue). Scale bar: $20 \mu \mathrm{m}$.

involved in attaching the act in cytoskeleton to the ECM. Paxillin was evenly distributed before MS-5 or HCEC cell sheet lifting. However, in lifted cell sheets, paxillin was enhanced and organized into cortical networks similar to the arrangement of act in bundles (Figure 6).

The histological analysis of cross-sections of lifted cell sheets revealed that two-week MS-5 sheets were composed of 4-5 well cell layers with an approximately 40 $\mu \mathrm{m}$ in thickness, and extracellular matrix was abundant. In contrast, two-week HCEC sheets were composed of approximately 2-3 layers with $10-20 \mu \mathrm{m}$ in thickness, and the extracellular matrix was undeveloped or absent (Figure 7A).

SEM images of decellularized MS-5 sheets confirmed abundant ECM depositions with three-dimensional tightly packed and well-organized fibrous networks. In contrast, ECM fibers in HCEC sheets were loosely packed with more spaces between fibers (Figure 7B). Densitometry analysis confirmed the presence of type I collagen main chain bands, $\alpha 1$ and $\alpha 2$, only in two-week
MS-5 sheets which were absent in cell extract samples from two-week HCEC sheets (Figure 7C and Figure 7D).

\section{Discussion}

Despite the wide use of pNIPAm-coated thermoresponsive surfaces, little is known about the main factors influencing the successful production of intact cell sheets. Several studies have used cell sheets as a model to investigate wound healing and to describe the mechanisms regulating cell sheet motilities during wound repair. The thought-provoking study, performed by Rosen and Misfeldt, showed that when confluent kidney epithelial (MDCK) cells were wounded, they enable to migrate into the denuded area as a cell sheet only after a threshold density was reached [49]. The authors suggested that the velocity of cells as a contiguous cell sheet could be the result of a force generated from the mutual pressures caused by the crowding cells. It was concluded that the confluent cells can be detached as a cell sheet only when its density is at or above that threshold density and they possess the property of motion as 


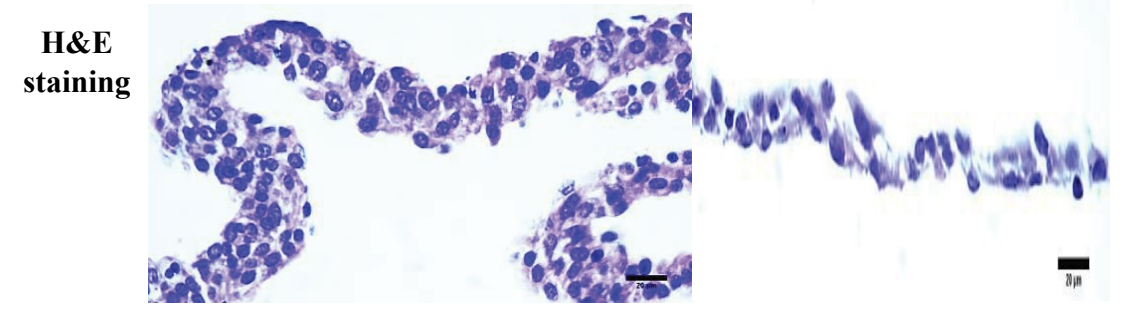

B

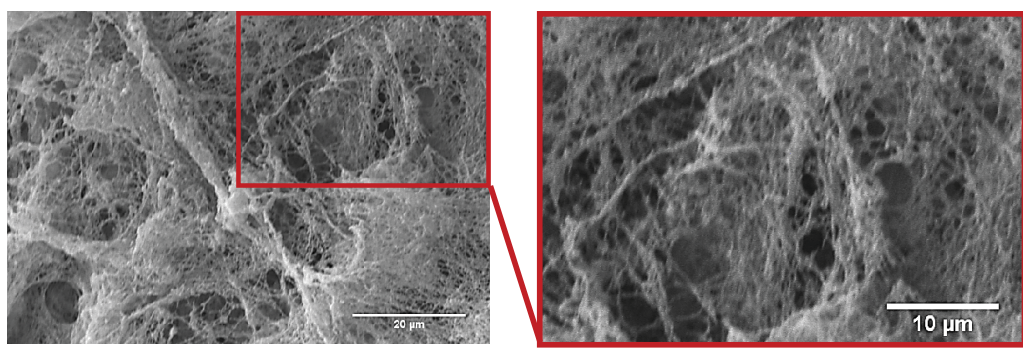

MS-5

HCEC

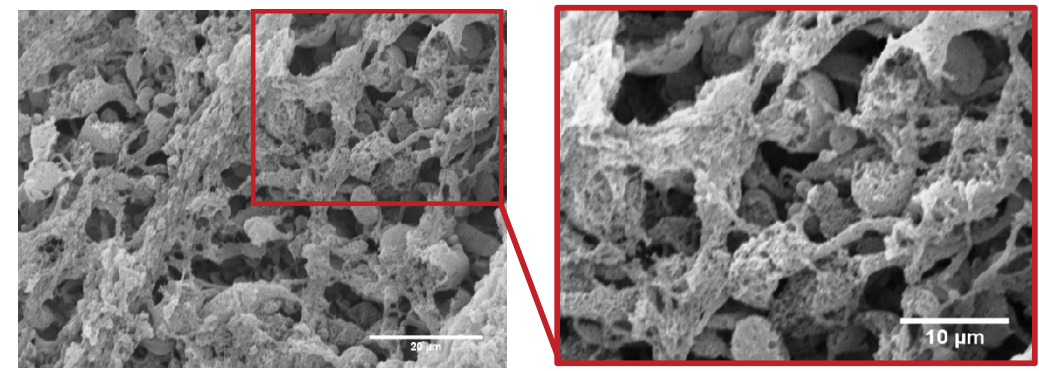

C
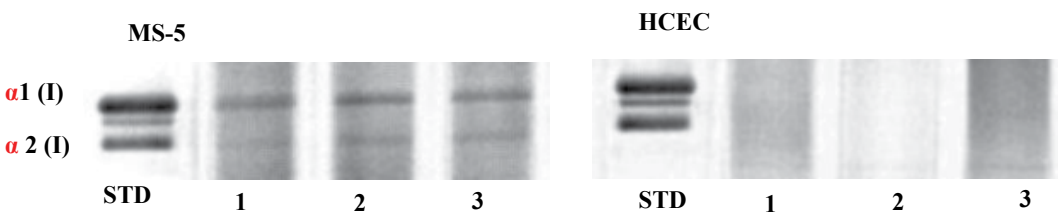

D

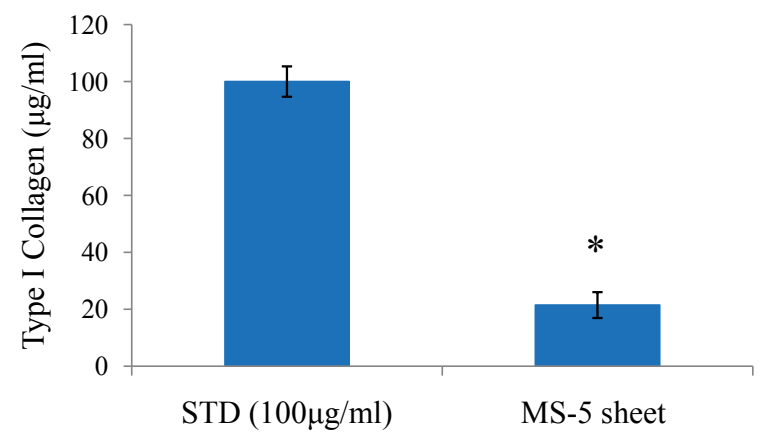

Figure 7: H\&E staining of two-week MS-5 and two-week HCEC cell sheets. MS-5 sheets were thicker and more compact than HCEC sheets. Scale bar: $20 \mu \mathrm{m} \mathrm{A)} \mathrm{Scanning} \mathrm{electron} \mathrm{microscopy} \mathrm{images} \mathrm{of} \mathrm{decellularized} \mathrm{cell} \mathrm{sheets:} \mathrm{Two-week} \mathrm{MS-5}$ sheets secreted more ECM than two-week HCEC sheets. Scale bar: $20 \mu \mathrm{m}$ and $10 \mu \mathrm{m}$; B) Electrophoretic profile (SDSPAGE): Stromal sheets produce type I collagen while epithelial sheets lack type I collagen; C) Graph showing type I collagen content in two-week MS-5 cell sheets; D) " $p<0.05$. Data are expressed as the mean \pm Standard Deviation (SD).

a united cell sheet. Another study analyzed collective cell behavior using a computational model [50]. In this model, Lober and co-authors used a series of parame- ters including reorganization of adhesion complexes and actomyosin-induced cell contraction to decipher the mechanisms of cellular motility. The study revealed 
that the collisions of neighboring individual cells cause the formation of coordinately moving high density tissue-like clusters. These studies corroborated our hypothesis that the trigger mechanism of cell sheet detachment from pNIPAm-coated substrate is closely related to the density-dependent forces. As temperature drops to $4{ }^{\circ} \mathrm{C}$, the cells lose their contacts with a pNIPAm coated film which dissolves in cell culture medium. As a result of being restricted in their movements, detaching and highly-packed cells release the inner pressure that promotes the further detachment of cells as a contiguous cell sheet. In other words, this might indicate that intact cell sheets could be detached from pNIPAm-coated substrates only when a confluent layer reaches the critical cell density. In our study, both lifted epithelial and stromal cells were confluent and formed multilayered sheets. Stromal MS-5 sheets, which were compared to epithelial HCEC sheets, were found to be able to detach as an intact cell sheet faster (10 \pm 3 min vs. $35 \pm 5 \mathrm{~min}$, respectively) and after a shorter period in culture ( 1 week vs. 2 weeks, respectively). Moreover, the number of cells needed for successful cell sheet detachment was significantly different between HCEC and MS- 5 cells $\left(0.8 \pm 0.1 \times 10^{6}\right.$ and $2.2 \pm 0.3 \times 10^{6}$, respectively; $\mathrm{p}<0.05)$. Taken together, this implies that the trigger mechanism of cell sheet detachment from pNIPAm films depends on cell type and requires high cell density cultivation.

High cell density results in contact inhibition and drives the cells to enter a quiescence state. In the present study, alamarBlue assay showed that lifted and reattached cell sheet's metabolic activity was the same as in control cells. Live/Dead staining revealed that the percentage of viable cells stained with calcein AM reached almost $100 \%$ on all tested samples before and after detachment and after reattachment. These data indicate that despite the culturing of cells at high density, the cell sheets remained viable and highly metabolically active. Our results corroborated the recent study showing that contact inhibited primary fibroblasts remain highly metabolically active resembling terminally differentiated cells like epithelial cells or cardio myocytes, which are characterized by very high energy consumption [51]. Another interesting study, published by Blagosklonny and co-authors, showed that contact inhibited cells did not undergo senescence and retained proliferative potential after splitting [52]. Together, these data and our present findings suggest that high density cell sheets may retain their biological activity after detachment and reattachment, indicating their potential application in cell sheet-based tissue engineering.

Cellular movements are driven by continuous and dynamic reorganization of actin cytoskeleton [53]. Huang, et al. previously revealed that lifted keratinocyte cell sheets exhibited changes in the distribution of actin cytoskeletal. It was shown that act in cytoskeleton is an essential contributor to cell sheet formation, its mechanical strength and cohesion [31]. The actin cytoskeleton of neighboring cells is connected through cell-cell junctions that seal cells together. Other major players in regulating tissue cohesion and homeostasis are cadherins. Cadherin ectodomains mediate cell-cell contacts, whereas the intracellular region functionally links cadherins to the underlying actin cytoskeleton $[54,55]$. It was shown that E-cadherin is critical for collective epithelial cell sheet movements [56] whereas $\mathrm{N}$-cadherin which is considered as a marker for the identification of bone marrow stromal cells [57] can also be involved in cell-cell contacts during the motions of high density cultured stromal cell sheets $[58,59]$. Shih and Yamada have shown that the up-regulation of dynamic cadherin-actin interactions in MDCK epithelial cells can be essential for collective cell movements in a three-dimensional matrix [60]. In the present study, lifted MS-5 and HCEC cell sheets significantly increased the fluorescence signal from cortical actin and cadherins at cell-cell junctions. Our results showed that lifted MS-5 and HCEC cell sheets lost cytoplasm actin but instead enhanced cortical actin fibers at cell-cell junctions. This implies that cell-cell junctions were sensitive to cell sheet detachment, and that the assembly of cadherins and actin fibers across intercellular junctions may represent a major mechanism that maintains the integrity of lifted cell sheets. ECM is another important factor that may accelerate tissue maturation in terms of mechanical properties and structural integrity. The thermoresponsive pNIPAm-coated substrates may offer significant advantage for cell sheet technology allowing for the preservation of cell-ECM contacts after detachment. Previously Cana van, et al. have shown that ECM remains preserved and attached to the cell sheets after rapid recovery from pNIPAm-coated surfaces $[61,62]$. The strong interactions between detaching cells and ECM might additionally facilitate rapid recovery of intact cell sheets. Microscopy analysis confirmed that MS-5 stromal sheets composed of higher number of cell layers with a dense network of ECM fibers whereas HCEC epithelial sheets revealed poor and undeveloped ECM formation. These data are in agreement with SDS-PAGE and complementary densitometric analysis which confirmed the deposition of type I collagen in MS-5 sheets. Therefore, ECM of MS- 5 sheets generated a stronger contractile force facilitating a rapid lifting from a substrate by physically pulling up the shrunken cell sheet. This might result in a higher speed of MS-5 cell sheet recovery in comparison with HCEC cell sheets. In addition, one-week MS-5 cell sheets were stronger and easily manipulated. In contrast, one-week HCEC sheets were more fragile and partly broken in culture that might 
be due to a low content of ECM components. Finally, the positive paxillin staining was observed in both stromal and epithelial lifted cell sheets that can indicate the presence of cell-ECM interaction in lifted cell sheets. The preserved ECM and focal adhesions can greatly facilitate cell sheet re-adherence. Therefore, the transplanted cell sheets can rapidly adhere onto tissues without suturing and can be successfully used for tissue reconstruction. Additionally, 3D tissue-like structure can be created in vitro by combining layers of cell sheets from different cell types. 3D culture will accelerate our understanding of the cellular and molecular mechanisms of organogenesis, yield insights into cellular basis of disease progression and enable the identification of molecular signals that promote tissue regeneration.

\section{Conclusions}

Taken together, the data show substantial changes in structural assembly of intercellular junctions of cell sheets undergoing force-dependent remodeling during detachment. The intact cell sheets lifted from pNIPAm-coated substrate are able to preserve structural integrity possibly due to being highly-reactive towards lifting that allowed them to rapidly reinforce their cytoskeleton network and cell-cell adhesions. The cell sheets acquire mechanosensitive properties if they reach critical cell density that depends on cell type. It is unlikely that ECM deposition play a key role in cell sheet detachment. However, the cells produced higher level of ECM may facilitate a more rapid cell sheet detachment at an earlier culture time. In addition, ECM and preserved focal adhesions that serve as mechanical linkages to the ECM promote successful reattachment of lifted cell sheets despite their shrinkage. Based on our results, we speculate that the dissolution of pNIPAm substrate might be an initial factor in the mechanism where together the accumulation of internal pressure within high density cell sheets, the assembly of cadherins and actin fibers across intercellular junctions and contractile force generated by ECM contraction result in contiguous cell sheet recovery.

The cell sheet harvesting using thin spin-coated pNIPAm films represents a convenient and cost-effective technique for $3 \mathrm{D}$ tissue engineering. This method has advantage of creating viable, metabolically active and open for manipulation cell sheets. The control of cell sheet characteristics including cell sheet density, structural integrity and the ability of rapid reattachment can improve the safety and efficacy of regenerative therapy. Understanding the mechanism of cell sheet formation and maturation is important for standardization and optimization of cell sheet engineering which has become an important tool in tissue engineering and regenerative medicine.

\section{Acknowledgement}

The authors acknowledge the facilities and technical assistance of Dr. Pierce Lalor from the Centre for Microscopy \& Imaging at the National University of Ireland, Galway (www.imaging.nuigalway.ie). The authors thank Dr. Siobhan Mc Mahon and Prof. Yuri Volkov for critical reading of the manuscript. The study has received funding from the Irish Research Council under grant agreement GOIPG/2016/654.

\section{Conflict of Interest}

The authors declare no competing interests.

\section{References}

1. Tanaka S, Kanetaka K, Fujii M, et al. (2017) Cell sheet technology for the regeneration of gastrointestinal tissue using a novel gastric perforation rat model. Surg Today 47: 114-121.

2. Syed-Picard FN, Du Y, Hertsenberg AJ, et al. (2016) Scaffold-free tissue engineering of functional corneal stromal tissue. J Tissue Eng Regen Med.

3. Owaki T, Shimizu T, Yamato M, et al. (2014) Cell sheet engineering for regenerative medicine: Current challenges and strategies. Biotechnol J 9: 904-914.

4. Shum AM, Che H, Wong AO, et al. (2017) A micropatterned human pluripotent stem cell-based ventricular cardiac anisotropic sheet for visualizing drug-induced arrhythmogenicity. Adv Mater.

5. Gupta N, Liu JR, Patel B, et al. (2016) Microfluidics-based 3D cell culture models: utility in novel drug discovery and delivery research. Bioengineering \& Translational Medicine 1: 63-81.

6. Zhang H, Liu S, Zhu B, et al. (2016) Composite cell sheet for periodontal regeneration: Crosstalk between different types of MSCs in cell sheet facilitates complex periodontal-like tissue regeneration. Stem Cell Res Ther 7: 168.

7. Monteiro N, Smith EE, Angstadt S, et al. (2016) Dental cell sheet biomimetic tooth bud model. Biomaterials 106: 167-179.

8. Neo PY, Teh TK, Tay AS, et al. (2016) Stem cell-derived cell-sheets for connective tissue engineering. Connect Tissue Res 57: 428-442.

9. Akimoto J, Takagi S, Nakayama M, et al. (2016) Transplantation of cancerous cell sheets effectively generates tumor-bearing model mice. J Tissue Eng Regen Med 10: E510-E517.

10. Okuda A, Horii-Hayashi N, Sasagawa T, et al. (2017) Bone marrow stromal cell sheets may promote axonal regeneration and functional recovery with suppression of glial scar formation after spinal cord transection injury in rats. J Neurosurg Spine 26: 388-395.

11. Kim JH, Joo HJ, Kim M, et al. (2017) Transplantation of adipose-derived stem cell sheet attenuates adverse cardiac remodeling in acute myocardial infarction. Tissue Eng Part A 23: 1-11.

12. Itokazu M, Wakitani S, Mera H, et al. (2016) Transplantation of scaffold-free cartilage-like cell-sheets made from human bone marrow mesenchymal stem cells for cartilage repair: A preclinical study. Cartilage 7: 361-372. 
Citation: Dzhoyashvili NA, Joyce K, Thompson K, et al. (2017) Fabrication of Functional High Density Cell Sheets for Tissue Engineering Using Spin-Coated Poly(N-isopropylacrylamide) Thin Films. Insights Stem Cell Res Ther 1(1):1-14

13. Miyagawa S, Domae K, Yoshikawa Y, et al. (2017) Phase I clinical trial of autologous stem cell-sheet transplantation therapy for treating cardiomyopathy. J Am Heart Assoc 6: e003918.

14. Mandai M, Watanabe A, Kurimoto $Y$, et al. (2017) Autologous induced stem-cell-derived retinal cells for macular degeneration. N Engl J Med 376: 1038-1046.

15. Tatsumi K, Okano T (2017) Hepatocyte transplantation: Cell sheet technology for liver cell transplantation. Curr Transplant Rep 4: 184-192.

16. Shimizu H, Ohashi K, Utoh R, et al. (2009) Bioengineering of a functional sheet of islet cells for the treatment of diabetes mellitus. Biomaterials 30: 5943-5949.

17. Kym D, Yim H, Yoon J, et al. (2015) The application of cultured epithelial autografts improves survival in burns. Wound Repair Regen 23: 340-344.

18. Yano F, Hojo H, Ohba S, et al. (2013) Cell-sheet technology combined with a thienoindazole derivative small compound TD-198946 for cartilage regeneration. Biomaterials 34: 5581-5587.

19. Watanabe K, Yamato M, Hayashida Y, et al. (2007) Development of transplantable genetically modified corneal epithelial cell sheets for gene therapy. Biomaterials 28: 745-749.

20. Kanai N, Yamato M, Okano T (2014) Cell sheets engineering for esophageal regenerative medicine. Ann Transl Med 2: 28 .

21. Kim YH, Kim DH, Shin EJ, et al. (2016) Comparative analysis of substrate-free cultured oral mucosal epithelial cell sheets from cells of subjects with and without Stevens-Johnson syndrome for use in ocular surface reconstruction. PLoS One 11: e0147548.

22. Healy D, Nash ME, Gorelov A, et al. (2017) Fabrication and application of photocrosslinked, nanometer-scale, physically adsorbed films for tissue culture regeneration. Macromol Biosci 17.

23. Moran MT, Carroll WM, Gorelov A, et al. (2007) Intact endothelial cell sheet harvesting from thermoresponsive surfaces coated with cell adhesion promoters. J R Soc Interface 4: 1151-1157.

24. Elloumi-Hannachi I, Yamato M, Okano T (2010) Cell sheet engineering: A unique nanotechnology for scaffold-free tissue reconstruction with clinical applications in regenerative medicine. J Intern Med 267: 54-70.

25. Tang Z, Okano T (2014) Recent development of temperature responsive surfaces and their application for cell sheet engineering. Regener Biomater 1: 91-102.

26. Dzhoyashvili NA, Thompson K, Gorelov AV, et al. (2016) Film thickness determines cell growth and cell sheet detachment from spin-coated poly( $\mathrm{N}$-isopropylacrylamide) substrates. ACS Appl Mater Interfaces.

27. Nash ME, Carroll WM, Nikoloskya N, et al. (2011) Straightforward, one-step fabrication of ultrathin thermoresponsive films from commercially available pNIPAm for cell culture and recovery. ACS Appl Mater Interfaces 3: 1980-1990.

28. Huang HL, Hsing HW, Lai TC, et al. (2010) Trypsin-induced proteome alteration during cell subculture in mammalian cells. J Biomed Sci 17: 36.
29. Pesirikan N, Chang W, Zhang X, et al. (2013) Characterization of Schwann cells in self-assembled sheets from thermoresponsive substrates. Tissue Eng Part A 19: 16011609.

30. Cerqueira MT, Pirraco RP, Santos TC, et al. (2013) Human adipose stem cells cell sheet constructs impact epidermal morphogenesis in full-thickness excisional wounds. Biomacromolecules 14: 3997-4008.

31. Wei Q, Huang H (2014) Characterization of partially Lifted Cell Sheets. Tissue Eng Part A 20: 1703-1714.

32. Wei Q, Reidler D, Shen MY, et al. (2013) Keratinocyte cytoskeletal roles in cell sheet engineering. BMC Biotechnol 13: 17.

33. Scarpa E, Mayor R (2016) Collective cell migration in development. J Cell Biol 212: 143.

34. Wang X, Enomoto A, Asai N, et al. (2016) Collective invasion of cancer: Perspectives from pathology and development. Pathol Int 66: 183-192.

35. Park JA, Atia L, Mitchel JA, et al. (2016) Collective migration and cell jamming in asthma, cancer and development. J Cell Sci 129: 3375-3383.

36. Park JA, Fredberg JJ (2016) Cell jamming in the airway epithelium. Ann Am Thorac Soc 13: S64-S67.

37. Friedl P, Gilmour D (2009) Collective cell migration in morphogenesis, regeneration and cancer. Nat Rev Mol Cell Biol 10: 445-457.

38. Collins C, Nelson WJ (2015) Running with neighbors: coordinating cell migration and cell-cell adhesion. Curr Opin Cell Biol 36: 62-70.

39. Pegoraro AF, Fredberg JJ, Park JA (2016) Problems in biology with many scales of length: Cell-cell adhesion and cell jamming in collective cellular migration. Exp Cell Res 343: $54-59$.

40. Deakin NO, Turner CE (2008) Paxillin comes of age. J Cell Sci 121: 2435-2444.

41. Turner CE (2000) Paxillin and focal adhesion signalling. Nat Cell Biol 2: E231-E236.

42. Yu JA, Deakin NO, Turner CE (2010) Emerging role of paxillin-PKL in regulation of cell adhesion, polarity and migration. Cell Adh Migr 4: 342-347.

43. Weber G, Bjerke M, DeSimone DA (2012) Mechanoresponsive cadherin-keratin complex directs polarized protrusive behavior and collective cell migration. Dev Cell 22: 104-115.

44. Hayer A, Shao L, Chung M, et al. (2016) Engulfed cadherin fingers are polarized junctional structures between collectively migrating endothelial cells. Nat Cell Biol 18: 13111323.

45. Lee E, Ewald ML, Sedarous M, et al. (2016) Deletion of the cytoplasmic domain of $\mathrm{N}$-cadherin reduces, but does not eliminate, traction force-transmission. Biochem Biophys Res Commun 478: 1640-1646.

46. McCloy RA, Rogers S, Caldon CE, et al. (2014) Partial inhibition of Cdk1 in G2 phase overrides the SAC and decouples mitotic events. Cell Cycle 13: 1400-1412.

47. Xing Q, Yates K, Tahtinen M, et al. (2015) Decellularization of fibroblast cell sheets for natural extracellular matrix 
Citation: Dzhoyashvili NA, Joyce K, Thompson K, et al. (2017) Fabrication of Functional High Density Cell Sheets for Tissue Engineering Using Spin-Coated Poly(N-isopropylacrylamide) Thin Films. Insights Stem Cell Res Ther 1(1):1-14

scaffold preparation. Tissue Eng Part C Methods 21: 77-87.

48. See EY, Toh SL, Goh JC (2008) Technique to accurately quantify collagen content in hyperconfluent cell culture. J Mol Histol 39: 643-647.

49. Rosen P, Misfeldt DS (1980) Cell density determines epithelial migration in culture. Proc Natl Acad Sci U S A 77: 4760-4763.

50. Löber J, Ziebert F, Aranson IS (2015) Collisions of deformable cells lead to collective migration. Sci Rep 5: 9172.

51. Lemons JM, Feng XJ, Bennett BD, et al. (2010) Quiescent fibroblasts exhibit high metabolic activity. PLoS Biol 8: e1000514.

52. Leontieva OV, Demidenko ZN, Blagosklonny MV (2014) Contact inhibition and high cell density deactivate the mammalian target of rapamycin pathway, thus suppressing the senescence program. Proc Natl Acad Sci U S A 111: 8832-8837.

53. Letort G, Ennomani H, Gressin L, et al. (2015) Dynamic reorganization of the actin cytoskeleton. F1000Res 4: 1000.

54. Yonemura S (2011) Cadherin-actin interactions at adherens junctions. Curr Opin Cell Biol 23: 515-522.

55. Rao MV, Zaidel-Bar R (2016) Formin-mediated actin polymerization at cell-cell junctions stabilizes E-cadherin and maintains monolayer integrity during wound repair. Mol Biol Cell 27: 2844-2856.

56. Hwang S, Zimmerman NP, Agle KA, et al. (2012) E-cadher- in is critical for collective sheet migration and is regulated by the chemokine CXCL12 protein during restitution. J Biol Chem 287: 22227-22240.

57. Ishimine H, Yamakawa N, Sasao M, et al. (2013) N-cadherin is a prospective cell surface marker of human mesenchymal stem cells that have high ability for cardiomyocyte differentiation. Biochem Biophys Res Commun 438: 753-759.

58. Theveneau E, Mayor R (2012) Cadherins in collective cell migration of mesenchymal cells. Curr Opin Cell Biol 24: 677-684.

59. Friedl $P$, Mayor $R$ (2017) Tuning collective cell migration by cell-cell junction regulation. Cold Spring Harb Perspect Biol 9.

60. Shih W, Yamada S (2012) N-cadherin-mediated cell-cell adhesion promotes cell migration in a three-dimensional matrix. J Cell Sci 125: 3661-3670.

61. Canavan HE, Cheng X, Graham DJ, et al. (2005) Cell sheet detachment affects the extracellular matrix: A surface science study comparing thermal liftoff, enzymatic, and mechanical methods. J Biomed Mater Res A 75: 1-13.

62. Canavan HE, Cheng X, Graham DJ, et al. (2005) Surface characterization of the extracellular matrix remaining after cell detachment from a thermoresponsive polymer. Langmuir 21: 1949-1955. 